\title{
Un demi-siècle d'évolution de la pensée en matière de structure des compagnies de chemins de fer
}

Maurice Wolkowitsch

\section{OpenEdition}

\section{Journals}

Édition électronique

URL : https://journals.openedition.org/rhcf/1298

DOI : 10.4000/rhcf.1298

\section{Éditeur}

Rails \& histoire

\section{Édition imprimée}

Date de publication : 10 février 2004

Pagination : 11

ISBN : 0996-9403

ISSN : 0996-9403

\section{Référence électronique}

Maurice Wolkowitsch, « Un demi-siècle d'évolution de la pensée en matière de structure des compagnies de chemins de fer », Revue d'histoire des chemins de fer [En ligne], 30 | 2004, mis en ligne le 02 septembre 2012, consulté le 22 avril 2022. URL : http://journals.openedition.org/rhcf/1298 ; DOI : https://doi.org/10.4000/rhcf.1298 


\section{Un demi-siècle d'évolution de la pensée en matière de structure des compagnies de chemins de fer}

«Les chemins de fer diffèrent de nos voies de communication ordinaire que parce qu'ils ne peuvent être exploités qu'en monopole... »

Discours d'un député de la Charente en 1844 (anciennes archives SNCF Région Sud-Ouest C6 AB : Formation de la Compagnie d'Orléans à Bordeaux et constitution du Chemin de fer du Centre).

« Le morcellement des compagnies, c'est si l'on peut parler ainsi, l'enfance de l'industrie des transports. À mesure que cette industrie se développe et s'éclaire, elle doit tendre à l'unité. L'unité est la condition nécessaire à toutes les institutions appelées à durer. Il était digne de la vigoureuse intelligence qui avait su ramener l'unité dans le gouvernement, de comprendre l'importance que pouvait avoir l'application du même principe à l'industrie... Nous aidons le gouvernement à faire jouir de nouveaux intérêts, de nouvelles populations, des bienfaits de l'unité... »

Extrait d'une lettre destinée à justifier la fusion des chemins de fer vers la Belgique et l'Angleterre, 1852 (anciennes archives SNCF Région Sud-Ouest $\mathrm{F}_{1} \mathrm{~B}_{7}$. Dossier relatif à la justification des fusions entre compagnies ferroviaires).

«Sans doute, il n'y a théoriquement aucune difficulté à ce qu'une grande compagnie exploite deux réseaux, l'un à voie large, l'autre à voie étroite [...]

Tout cela ne serait pas sans inconvénients mais serait possible, mais elle aurait toujours à se défendre contre son titre de grande compagnie, contre l'inévitable tendance de l'État, du public à exiger d'elle comme minimum ce que l'on oserait jamais demander comme maximum à une compagnie locale, protégée par sa faiblesse même ; l'exploitation économique lui serait forcément rendue impossible. Les petits chemins de fer aux petites compagnies, telle est la loi raisonnable et nécessaire... »

Gustave Noblemaire, "Les chemins de fer départementaux », 1889, in Hommes et choses de chemins de fer, Paris, Paul Dupont, 1905, p. 84113, citation p. 86. 
